Issue 20: March 2021

\title{
Editorial
}

\author{
Jim Donohue \\ Manchester Metropolitan University \\ Nicola Grayson \\ University of Manchester
}

Andy Hagyard

Independent

Jenny Hillman

Open University

Eleanor Loughlin

Durham University

\section{Cathy Malone}

Oxford Brookes University

Craig Morley

University of Manchester

\section{Gita Sedghi}

University of Liverpool

\section{Alicja Syska}

University of Plymouth

It has now been a full year since the pandemic became a defining feature of our professional and personal lives, leaving an indelible mark on how we think, engage, and produce. Our workloads are higher and strains on our time feel harder; our patience and resilience have been tried so ceaselessly and mercilessly that we might wonder what the limit is for our capacity for change and reinvention. And yet, we keep creating, producing, innovating and writing, with our experiments ever bolder and our hopes ever brighter.

Writers will keep writing and publishers will keep publishing! Thus, in this Issue 20, we bring you three new papers, one case study, and four book reviews, whose summaries follow. 
In their paper, Charles Buckley, Eli Saetnan, Amelia Gerber, Joanna Cheetham, Thomas Price, Jenna Kenyani and Alan Greaves explore the impact writing support sessions (writing workshops and retreats) have on reducing the stress and anxiety associated with thesis writing, and academic writing more generally. This impact was investigated through a mixed-methods approach. Participants' feelings of anxiety and stress were quantified through pre and post session surveys. Qualitative data on students' experiences of the writing support was gathered through focus-group interviews. The findings from this data suggested that participation in writing workshops and retreats had a positive impact on reducing anxiety and stress surrounding thesis writing by creating a safe environment that helped to build up students' sense of empowerment and confidence.

In the second paper in this volume, Samantha King analyses how students develop and use metadiscourse, the language used to guide readers through a text, in their writing, and investigates whether the use of metadiscourse impacts student grades. To achieve this, a corpus of summative written assignments was collected from 67 undergraduates studying a health discipline. These assignments were then analysed using software developed for the field of corpus linguistics to identify how students used metadiscourse in their writing. King's findings contrast with those of previous studies and suggest there is very little difference, in the health disciplines at least, in the use of metadiscoursal features helping students earn higher grades. Nevertheless, King uses the findings from this investigation to suggest that learning developers should include some level of metadiscourse training in their teaching.

Chris Maharaj, Erik Blair and Margo Burns turn their attention to the impact of student mentoring on the academic performance of undergraduate students identified as 'at risk'. Based on an early intervention programme designed to improve students' success, and using Attribution Theory, the study demonstrates that mentoring which guides students to find solutions to the challenges they face can be a powerful determinant of their academic performance. While the authors are cautious in drawing larger conclusions from the study, they feel confident to affirm that the mentoring process, regardless of its length or quality, has a positive impact on students' sense of self-worth and efficacy. Recommendations from the analysis include expanding mentorship schemes and implementing both one-toone and group mentorship as required by a particular context. The study is dedicated to the late Dr Margo Burns who sadly passed away before the publication of this issue. 
The case study by Lucy Gill-Simmen examines the use of Padlet to promote cognitive engagement among undergraduate marketing students. After a previous cohort reported a high level of difficulty in completing one particular assessment in writing, Padlet was introduced to facilitate greater engagement and interest in the task. Correctly predicting that the more creative and technology-based instructional design would make the assessment more attractive, the results of the study show that the students considered Padlet not only a great opportunity to demonstrate their knowledge visually but also an enjoyable experience and a valuable aid in learning. While adopting technology in the classroom should never be an end in itself, this case study provides a good example of how effectively it can be incorporated if underpinned by solid pedagogic goals.

Anne Elizabeth Davey and Hazel Messenger review the book Skills for business and management by Martin Sedgley. The book aims to help students embarking on a business and management course at university to overcome transition hurdles. It is designed around five key areas relevant to the discipline: independent learning, time management, academic reading, academic writing and group working. Both reviewers agree that the text would provide valuable support for academic staff, academic mentors and learning designers who could use the content to promote learning development in their own contexts.

Samantha Ahern reviews the book Maximizing the impacts of academic research by Patrick Dunleavy and Jane Tinkler. The tagline of this book is 'How to grow the recognition, influence, practical application and public understanding of science and scholarship'. This is a very useful reference text for those who are undertaking doctoral studies or for early career researchers. The content of the book is organised into three parts: academic impacts, academic and external impacts, and external impacts.

\section{Finally, Teresa De Fazio reviews the book Challenging the Teaching Excellence} Framework: diversity deficits in higher education evaluations by Amanda French and Kate Carruthers Thomas. The text details the contextual background to the Teaching Excellence Framework (TEF) and the underlying drivers that contributed to its development and adoption. It questions the interpretation of excellence adopted by the TEF and limitations of how it is measured by the Framework from the perspective of diverse learners and staff. It is an important reading for anyone who is interested in the 
issue of excellence in higher education and its measurement; in particular, from the perspective of equity and diversity.

We hope that in this collection of articles, our subscribers and readers will find thought provoking and stimulating material.

We also want to take this opportunity to thank our wonderful reviewers whose critical reading of submissions and thoughtful feedback and recommendations have made invaluable contributions to the quality of articles we publish.

Our heartfelt appreciation for the time, expertise, and work it took to review papers in this issue goes to the following reviewers:

Monica Behrend, Australia

Vesna Bogdanović, Serbia

Nicola Grayson, UK

Robert Ping-Nan Chang, UK

Sonja Rewhorn, UK

Nkaepe Olaniyi, UK

Stephanie Doehler, UK

Steve Peters, UK

Gabrielle Smith, Austria

Alison Gilmour, UK

We look forward to talking to our readers and contributors at the ALDinHE Annual Conference soon!

With best wishes,

The JLDHE Editorial Board 